\title{
Construction of sports facilities and playgrounds in the Moscow region as a factor of sustainable development
}

\author{
Igor' Pryadko ${ }^{1, *}$ \\ ${ }^{1}$ Moscow State University of Civil Engineering, 26, Yaroslavskoe shosse, 129337, Moscow, Russia
}

\begin{abstract}
The article analyzes the measures, taken in and around Moscow to create a comfortable architectural and urban planning environment. Special focus has been placed on the construction of childcare and art centres, as well as sports facilities. The author uses statistical data and news reports about the launch of a network of facilities designated for children and teenagers. The article outlines the most recent trends in the construction of childcare facilities. The purpose of the research is to identify the top-priority focus of urban development and urban planning. The author emphasizes the ability of proper architectural environments to ensure the successful social involvement of children, residing in the capital. The work analyzes the state of affairs in this area of research and makes projections in terms of the sociocultural evolution of urban areas.
\end{abstract}

\section{Introduction}

Over the last ten years, an unprecedentedly ambitious construction programme has been launched in the Moscow metropolitan area, or in the megalopolis and the Moscow region. The programme entails the development of the local amenity/community infrastructure to make sure that schools, preschool institutions, institutions of culture and facilities of critical infrastructure are located within walking distance of residential areas. Schools, childcare centres, institutions of culture, hospitals and healthcare institutions are being built within the framework of integrated spatial development programmes launched in New Moscow, in the southern and south-eastern parts of the capital, in the towns located northwest and southwest of the capital. These facilities are built in close proximity to the residential areas to ensure that the educational needs of young urban residents are catered for. The construction of entertainment areas and playgrounds is equally important (this idea will be developed in the first section of this research paper). The amount of construction work performed is impressive. However the true needs of children and teenagers are hard to identify. The author is going to fill this gap in this article.

It is generally believed that the urban environment is complex and segmented, same as our society. Hence, the urban architectural environment must cater for the needs of the maximal number of population categories and versatile social groups (refer to $[1,2,3]$ for their comparison). For example, any urban environment should cater for the

\footnotetext{
* Corresponding author: priadcko.igor2011@yandex.ru
} 
entertainment/leisure needs of young people, that translates into better access to entertainment and sports facilities. Children, fond of any branches of art, must have access to art studios and clubs. In response, young parents need driveways for baby carriages and sledges. A barrier-free environment is vital for elderly and handicapped urban residents. A properly organized architectural environment is a decisive factor boosting social engagement and enculturation of the younger generation.

The contributing author of New Districts emphasizes that "every Moscow schoolchild can use his or her sports talent [4]. Good sports performance, demostrated by the schoolchildren residing in Moscow and the Moscow Region, has drawn the attention of international organizations and fund. "Their successes, says the author, is a natural result of the education-focused efforts exerted by the Moscow authorities" [4]. Pre-school education is a condition of high performance in sports (advanced educatioal technologies are covered in more detail in [5]). A good sports and fitness environment at childcare centres and schools is a must for a healthy nation and a condition of future sports records. That's why the author provides several examples of comfortable sports grounds arranged for children around Moscow (in particular, the author has analyzed the state of affairs in Naro-Fominsk, Mytischi, and Schelkovo districts), and in several districts of Moscow. Access to art studios and science clubs are equally important for the younger generation. Towards this end, skill contests and academic competitions are held, and versatile clubs are established in the Moscow region (this issue is discussed in more detail further in the text of the work).

Taking care of the younger generation is an important task; therefore, the expenditure on health institutions for children and teens, or the so-called "children's health sector" keeps growing. This trend looks natural : the maturity of any society is manifest in the attitude to old people and children. Moscow and the Moscow Region are no exception : they accommodate sports centers for children, new childcare facilities, schools, clubs and art centres commissioned by construction companies, while municipal authorities in and around Moscow establish sports schools for children and teenagers, allot land plots that will accommodate children's leisure activities, finance children's covalescence homes and health resorts that are in operation and build the new ones. Budgetary amounts used to fund these activities are substantial, and they keep growing. Further we will focus on the two actions that allow to increase the number and size of convenient venues designated for children's leasure activities, including the construction of playgrounds and leisure venues, daycare and medical centres.

\section{Materials and Methods}

The author used a questionnaire to analyze a comfortable architectural environment as an instrument of social engagement of children and teenagers. The author presents the findings of a pilot sosiological survey conducted by Moscow architects and civil activists among the children and teenagers who reside in the city and attend its sport venues and playgrounds. The survey also takes account of the statistical data on the cost of programs for teenagers and children, implemented in the Russian capital and in the districts of the Moscow Region. The statistical data was contributed to the reports, issued by the legislative authorities of Moscow and the Moscow Region and published in electronic media, newspapers and magazines in the Moscow Region.

\section{Results}

A playground is a play area, where children master the rules and regularities of interpersonal communication. A comfortable urban environment for children is an 
instrument used to accomplish one of the most important social tasks, that is, physical and spiritual development of the young generation. A living environment that is comfortable for young parents and their children, who need play areas near their homes, can help to decelerate the population decline. This idea is promoted by a Moscow architect, who launched a pilot survey to study the urban architecture for children. "We have decided, says this specialist, to study this issue in the context of a school homework. We have identified that no one is professionally involved in designing the environment for Moscow children, although it is a condition of the patriotic upbringing: any person remembers the place where he or she felt comfortable in his childhood." Indeed, the devotion to one's native country originates from the devotion to the place where a person was born and where he or she grew, where he or she lives and works. This is his/her "tiny motherland."

Designers, employed with CAU Research, made their contribution at the final stage of the playground/sport site design [6].

Alexander Asafov, an architect, argues that the most popular sports grounds have versatile constructions. He argues that only five out of thirty playgrounds (about $17 \%$; see Figure 1) comply with these evident requirements. $70 \%$ of playgrounds were unused, as they were located in well-guarded yards, and therefore, their high-quality constructions could not be used by children (Figure 2).

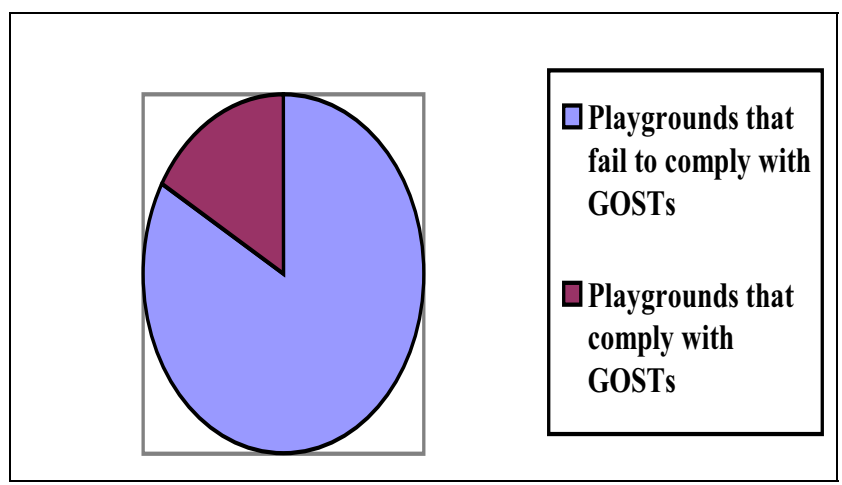

Fig. 1. Playground facilities.

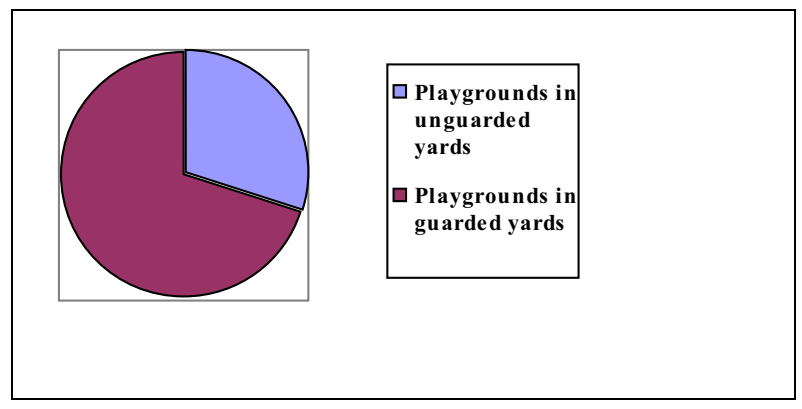

Fig. 2. Guarded (inaccessible) and unguarded (easily accessible) playgrounds.

The researchers appreciate the fact that some swings and merry-go-rounds are customized for handicapped children, although may Muscovites do not know how to use these customized facilities [7]. However, A. Asafov believes that playground designs take no account of children's preferences. Children, residing in megalopolises, would prefer shooting galleries, punchbags, rope ladders, jungle gyms, and rent-a-bikes [7]. However all these items could be concentrated in sports centres and out-of-school education facilities. 


\section{Community services and their financing in Moscow and towns of the Moscow Region}

The authorities of Moscow and the Moscow Region believe that the construction of playgrounds and arrangement of sports grounds is a matter that needs special attention.

Let's take a look at the statistical data. The statistical information on the Naro-Fominsk district, whose part was annexed to New Moscow, was made public by M.B. Zakharova, a deputee of the Moscow Regional Duma, in her report. 10 million roubles were alloted to enterprises and institutions in order to have the electors' mandates fulfilled pursuant to the Moscow Regional Law of June 18, 2012 № 80/2012 “Supplementary measures aimed at the strengthening of the material and technical base of the housing and utilities infrastructure, healthcare, physical culture, education, media and population safety assurance." Further, the deputy spoke about the disbursement of this amount (see Figure 3):

2 million 290 thousand roubles were disbursed to secondary education institutions;

3 million 960 thousand roubles were disbursed to preschool centres of education;

1 million 450 thousand roubles were disbursed to institutions of culture;

1 million roubles was disbursed to healthcare institutions (the purchase of ambulances and equipment);

500 thousand were spent for the maintenance of the utilities infrastructure and installation of playgrounds in Kalininets village;

800 thousand roubles were spent as the financial aid provided to disadvantaged social groups [8].
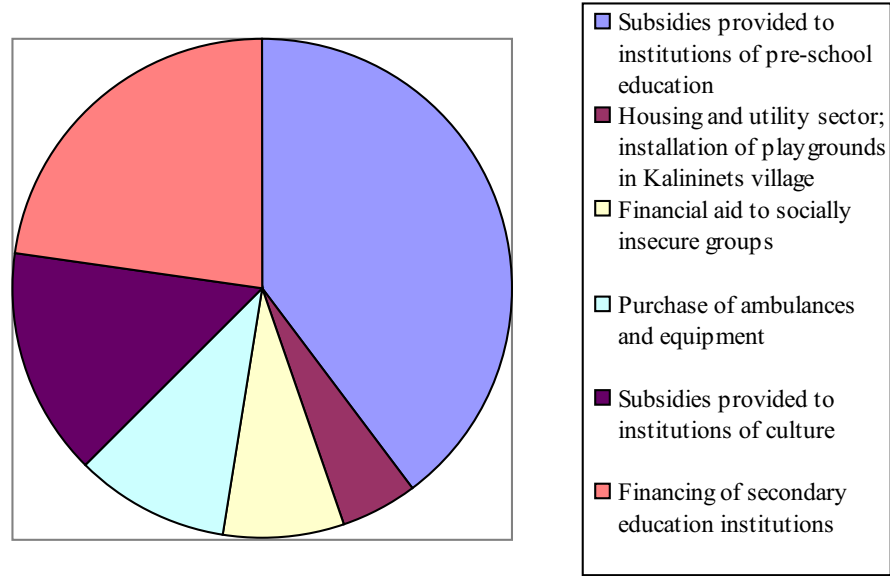

Fig. 3. Breakdown of social security financing in the Naro-Fominsk district.

We focus on the following two positions : financial aid to socially insecure groups, including retired residents with limited mobility and mothers having many children, etc.., on the one hand, and the construction/reconstruction of playgrounds and sports grounds in several towns and villages of the Moscow Region, on the other hand, totaling 1 million 300 thousand roubles.

Unlike other municipalities, Naro-Fominsk municipal district spends substantial amounts on social security: 
7 million 500 thousand roubles were spent by the Naro-Fominsk municipal district (the amount is ditributed among nine settlements);

1 million was spent by the Podolsk municipal district (renovation in Dubravushka childcare centre № 29);

1 million 400 roubles were spend by the Mozhaisk municipal district (renovation, purchase of furniture and equipment by municipal educational institutions in two settlements);

100 thousand roubles was spend by Molodezhny Closed administrative territorial unit (purchase of furtniture and equipment for childcare centre № 39) [8].

These amounts can be compared with social security disbursements in Mytischi : 34 million 539 thousand roubles were spent on the overhaul of childcare centres and schools there [9]. The social security amounts allocated for these purposes by the authorities of the capital, are much larger. In 2020, the capital and the Moscow Region spent larger amounts on the recreation and healthcare of children deprived of parental care, the medical treatment of orphans, sports events, etc. According to A. Shaposhnikov, Chairman of the Moscow City Duma, over 2.5 billion roubles were invested into the continued implementation of the long-term project entitled "Art for children" [10].

\section{Facilities constructed and to be constructed}

The construction of social security facilities and institutions of pre-school education is a vital contribution to a comfortable architectural environment. The relevance of this problem is realized both in the meganolopolis and its environs. However, few Moscow districts have taken any action. The construction of new childcare centres means the mobility of young mothers, their reintegration into society and adaptation to urban living. A kindergarten can take care of a baby and facilitate his mother's social and professional self-fulfillment by getting mothers back into society. Children do sports in kindergartens; thus, they grow healthy and prepare for future activities in the company of children of the same age. Civil engineers and urban planners design friendly environments, full of leisure areas for urban residents, including children and teenagers [11].

Let's focus on the facts listed in the periodicals published in the Moscow Region.

The problem of construction of pre-school childcare centres is resolved in the NaroFominsk district in the following way. On October 25, 2015, several new groups of children were formed in the local kindergartens within the framework of the programme aimed at increasing the number of children at childcare centres. According to the news alerts, published by the local media, the number of children was increased by kindergarten № 22 in Aprelevka and kindergarten № 29 in Ateptsevo. In 2016, local kindergartens admitted nineteen supplementary groups of children; therefore, over 800 children could attend kindergartens there at a time [12]. Local authorities believe that the defficiency of childcare centres is one of the most relvant problems in the district. It should be resolved both by admitting more children to childcare centres and by building new childcare centres in the district. Besides, other inefficient institutions can be converted into childcare centres. Local executive authorities admit that the construction and reconstruction of over a dozen kindergartens was not completed within the prescribed period of time [12] (refer to [13] for comparison purposes). Several kindergarten buildings were overhauled and reconstructed in Naro-Fominsk (kindergartens №2, №12, №20 и №3), Vereya, Aprelevka, and Selyatino. New kindergarten buildings are being built in Kalininets and Aprelevka. The part of a building was returned to kindergarten № 45 in Kiyevsky village, annexed to Moscow as one of it "new" districts. A new group was established in kindergarten № 52 in Vereya. Local media reported that 300 thousand roubles were spent on the construction of a fence around the territory of kindergarten № 50 in Volchenki village. 
In December 1, 2020, a new kindergarten was opened in Salaryevo Park, the district that accommodates the main transportation hub connecting the settlements of New Moscow. A new three-storied kindergarten building welcomes three hundred children [14]. Representatives of the municipal authorities emphasize that kindertgartens and residential houses are commissioned there simultaneously. In September 2020, a school and a kindergarten were commissioned at the same time. Buildings of educational institutions are built to individual designs. They are technologically advanced and comply with the most recent building standards.

However the establishment and construction of pre-school educational institutions is accompanied by a number of problems. In the context of the reforms that date back to the 90 ies of the 20th century, several pre-school institutions were closed. For example, one of three kindergartens was converted into a sports facility, and several premises of another kindergarten were occupied by the Centre of Culture in Kiyevsky village, they were returned to the kindergarten only after the village was annexed to Moscow. The construciton of kindergartens is intensive in Mytishchi and Schelkovo districts. In Sverdlovsky village, SU-22 development company has constructed the first kindergarten in twenty years; its erection « «was only only started, but also completed» [15, c.3]. However the facility could not be commissioned for a long time because of « a conflict with the residents of private homes, who refused to leave a land plot designated for a playground" [15]. The local news paper has disclosed the problem: « The kindergarten has no land for outdoor activities. This plot is occupied by the three houses, and their owners are not going to move to new places of residence closer to the village centre [15].

\section{Organizing the leisure time of children and teenagers}

Let's address the issue of organizing of leisure time of local children and teenagers as one of the most relevant social problems in a contemporary city. The community centre, located in Naro-Fominsk, has regularly featured artistic events. It hosts frequent children's contests, including those of national scale. The "Glory to the homeland" all-Russian contest is among the events of this kind. Besides this contest, centres of culture and sports in the towns of the Moscow Region hold the "Sports for everybody" competition, Annual Moscow Soccer Championships, and other sports competitions. Urban administrations draw particular attention to the material resources of children's centres of culture and sports. In 2020, weight lifting competitions, held within the framework of the "Sports for everybody" event, gained popularity. Last November, local competitions were held in the sports centre of Moskovsky (a settlement, annexed to Moscow as a new district. The competition was designated for young sportsmen [16].

The construction of facilities for handicapped teenagers, children with reduced mobility, mental disorders, and psychosomatic disturbances, visually impaired children, disabled children in wheelchairs, is also of substantial social significance. The social value of these institutions is regularly highlighted by the local periodicals published in the Naro-Fominsk district of the Moscow Region and newly annexed Moscow districts. The article written by E. Skripko highlights the operation of Skazka rehabilitation centre. "All kinds of rehabilitation services are provided to sick children there, starting from comprehensive medical care and ending with psychological counselling provided to sick children and their parents. The rehabilitation centre has five departments, scattered about the territory of the district. They accommodate 55 patients. It is a hospital department, department of medical and social rehabilitation, department of psychological and teaching aid, a daycare centre, and an administrative department" [17].

A major programme for the reconstruction of medical centres in new Moscow districts was launched in 2020 and 2021. 137 buildings are to be renovated, the majority of which 
were built about fifty years ago. Bearing walls and utility systems are to be renovated. Besides, these health centres will feature a new level of comfort for patients and doctors, including a congenial atmosphere, cozy recreation areas and waiting halls. The premises will feature easily comprehensible routes, comfortable rooms, etc. [11].

\section{Conclusions}

The analysis of the news items, published by the media agencies, and the poll findings have made it possible to draw the following general conclusions. The development of a comfortable living environment means self-fulfillment and satisfaction of cultural needs. In our article, we attempted to provide solutions to this problem. We have proved that the construction of recreation areas, designated for children and teenagers, may be accompanied by minor misunderstandings, triggered by conflicts of interests arising between versatile social groups. Model problem solving cases are described in the article. The author also analyzed insignificant conflicts triggered by the construction of childcare institutions. The statistical data, provided in this article, supports the conclusion made by $\mathrm{V}$. Zhidkin, Director, Department for Development of New Territories. In his interview he said that infrastructural facilities and special-purpose buildings are being constructed concurrently with residential housing. Indeed, since July 2012, 70 facilities, including 51 kindergartens and 19 schools [18] (refer to [19] for comparison purposes), have been built in New Moscow. The social infrastructure of New Moscow will keep pace with the one of the city's older districts.

\section{References}

1. A. Boltaevsky, I. Pryadko, Sociodynamics 3, 1 (2016) DOI: 10.7256/24097144.2016.3.18043

2. Z.I. Ivanova, N.V. Danilina, M.A. Slepnev, E3S Web of Conferences 91, 05012 (2019) DOI: https://doi.org/10.1051/e3sconf /2019910

3. A. Mottaeva, MATEC Web of Conferences 193, 01022 (2018) doi.org/10.1051/matecconf/201819301022

4. New Districts 48(364), 4 (2019)

5. L.A. Belyaeva, I.G. Chugaeva, E.V. Berezhnova, Advances in Social Science, Education and Humanities Research 447, 60-64 (2020)

6. A. Asafov, Metro (2013)

7. A. Posmitnaya, Metro (2013)

8. M.B. Zakharova, Osnova (2013)

9. A. Mottaeva, J. Ćetković, Advances in Intelligent Systems and Computing 692, 11511159 (2018) doi: 10.1007/978-3-319-70987-1_123

10. L. Vasnetsova, New Districts 49(415), 5 (2020)

11. V. Mezentsev, New Districts 1(417), 2 (2021)

12. Panorama NF 7, 5 (2016)

13. A. Mottaeva, As. Mottaeva, Int. J. of Applied Eng. Research 1, 11(2016)

14. D. Sokolova, Moskovsky Today 47(217), 1 (2020)

15. A.V. Bataev, A.A. Gorovoy, A.B. Mottaeva, Proceedings of the 32nd International Business Information Management Association Conference, IBIMA 2018 - Vision 
2020: Sustainable Economic Development and Application of Innovation Management from Regional expansion to Global Growth, 102-114 (2018)

16. S. Gavrilova, Moskovsky Today 44(214), 8 (2020)

17. E. Skripko, City Centre 08(327), 5 (2021)

18. L. Vasnetsova, New Districts 50(416), 3 (2020)

19. I. Pryadko, Urbanism 2, 38 (2017) DOI: 10.7256/2310-8673.2017.2.23036 